\title{
A Method for Predicting the Effects of Specimen Geometry and Loading Condition on Fatigue Strength
}

\author{
Chengqi Sun ${ }^{1,2, *}$ and Qingyuan Song ${ }^{1,2}$ \\ 1 State Key Laboratory of Nonlinear Mechanics, Institute of Mechanics, Chinese Academy of Sciences, \\ Beijing 100190, China; songqingyuan@imech.ac.cn \\ 2 School of Engineering Sciences, University of Chinese Academy of Sciences, Beijing 100049, China \\ * Correspondence: scq@lnm.imech.ac.cn; Tel.: +86-10-8254-3968
}

Received: 19 September 2018; Accepted: 8 October 2018; Published: 10 October 2018

\begin{abstract}
Specimen geometry and loading condition usually have a great influence on the fatigue strength of metallic materials, which is an important issue in evaluating the reliability of component parts. In this paper, a rotating bending fatigue test is performed at first on an hourglass specimen and a notch specimen of a high strength titanium alloy. Experimental results indicate that, in terms of local stress, the notch specimen endures higher fatigue strength in comparison with the hourglass specimen due to its relatively smaller control volume. Then, a probabilistic control volume method is proposed for correlating the effects of specimen geometry and loading condition on the fatigue strength based on Weibull distribution and the concept of control volume. A simple formula is obtained for the fatigue strength in relation to control volumes, in which the parameter is the shape parameter of Weibull distribution of fatigue strength. The predicted results are in good agreement with the present experimental data for high strength titanium alloy and the data for the high strength steel and the full scale EA4T axle in the literature.
\end{abstract}

Keywords: notch effect; size effect; loading condition; fatigue strength; control volume; titanium alloy

\section{Introduction}

The effects of specimen size, notch geometry, and loading condition on fatigue behavior of metallic materials are important topics in the fatigue research field, which is of great importance in evaluating the fatigue strength of structure components.

Much research has been carried out on the effects of specimen geometry and loading condition on fatigue behavior of metallic materials [1-8]. For example, Furuya [9] investigated the effect of specimen size on the very high cycle fatigue behavior of high strength steels, and showed that large specimens endured lower fatigue strengths due to the appearance of larger inclusions in control volumes (risk volumes). Kuguel [10] introduced a highly stressed volume method for predicting the fatigue strength of notched specimens. In this method, the fatigue notch factor $K_{f}$ and the elastic stress concentration factor $K_{t}$ were correlated by $K_{f} / K_{t}=\left(V_{n} / V_{s}\right)^{a}$, where $V_{n}$ and $V_{s}$ were volumes (the region no less than $95 \%$ of the maximum stress) for the notched and smooth specimens, respectively, and $a$ was a material constant determined by fitting the fatigue strength and the highly stressed volume. Lin \& Lee [11] studied the effect of highly stressed volume on the fatigue strength of austempered ductile irons under rotating bending and axial loading fatigue tests, and showed that the highly stressed volume method was able to predict the effects of notch and loading condition on fatigue strength. Leitner et al. [12] investigated the statistical size effects on the fatigue strength of notched electroslag remelted 50CrMo4 steel components under uniaxial and multi-axial loadings. It was indicated that the highly stressed surface concept might be preferably applied in case of surface failure modes, while for the highly stressed volume concept, an upper threshold value was needed in advance 
in order to obtain a proper fatigue strength assessment. Lanning et al. [13] investigated the effect of notch on high cycle fatigue strength of a Ti-6Al-4V alloy based on the weakest-link model. Bažant and Novák [14] developed a probabilistic nonlocal theory for quasibrittle fracture initiation and specimen size effect, in which the failure probability at a material point was assumed to be a power function of the average stress in the neighborhood. Makkonen [15] proposed a method for predicting the statistical size effect in the fatigue limit of steels based on the hypothesis that a specimen under cyclic loading could form a sample of initial cracks and the larger specimen had the larger sample of initial cracks. Susmel \& Taylor [16] extended the critical distance theory for predicting the fatigue life of notched components in medium cycle fatigue regime. Notably, the results of Härkegård \& Halleraker [17] indicated that the Weibull weakest-link method and the highly stressed volume method gave better predictions than the Neuber's and Peterson's, the peak stress, and the critical distance methods.

In this paper, the effects of specimen geometry and loading condition on the fatigue strength of metallic materials are investigated based on the statistical theory and the concept of control volume (i.e., the highly stressed volume). A rotating bending fatigue test is at first performed for the effect of notch on the fatigue behavior of a high strength titanium alloy. Then, a method is proposed for the effects of specimen geometry and loading condition on the fatigue strength based on the statistical theory and the concept of control volume. The predicted results are compared with the present experimental data and the data in literature. The difference is also discussed for the proposed method, the highly stressed volume method, and the Weibull weakest-link method.

\begin{tabular}{|ll|}
\hline Nomenclature & \\
A parameter & $V$ volume \\
a parameter & $V_{A}$ control volume of specimen A \\
$B$ parameter & $V_{B}$ control volume of specimen B \\
$F(x)$ Weibull distribution function & $V_{C}$ control volume of referring specimen $C$ \\
$h$ thickness & $x$ depth from the surface \\
$k$ shape parameter of Weibull distribution & $\chi^{\prime}$ relative stress gradient \\
$K_{t}$ stress concentration factor & $\gamma$ location parameter of Weibull distribution \\
$N$ number of cycles to failure & $\lambda$ scale parameter of Weibull distribution \\
$N_{0}$ number of cycles at the knee point & $\sigma$ stress \\
$N_{f}$ number of cycles to failure & $\sigma_{a}$ stress amplitude \\
$N_{k}$ number of cycles to failure, $k=1,2, \ldots, n$ & $\sigma_{A}$ fatigue strength of specimen A \\
$N^{\prime}{ }_{k}$ a given number of cycles to failure & $\sigma_{B}$ fatigue strength of specimen B \\
$n$ number of specimens & $\sigma_{C}$ fatigue strength of referring specimen C \\
$n_{A}$ integer part of $V_{A} / V_{C}$ & $\sigma(x)$ maximum principle stress in depth $x$ \\
$n_{B}$ integer part of $V_{B} / V_{C}$ & $\sigma_{k}$ fatigue strength, $k=1,2, \ldots, n$ \\
$R$ stress ratio & $\sigma^{\prime}{ }_{k}$ fatigue strength \\
$S_{A}$ control surface of specimen A & $\sigma_{\text {max }}$ maximum principle stress at the surface \\
$S_{B}$ control surface of specimen B & \\
\hline
\end{tabular}

\section{Experimental Material and Method}

The material tested is a high strength titanium alloy Ti-6Al-2Sn-2Zr-3Mo-X. The tensile strength is $1072 \mathrm{MPa}$, and the yield strength is $978 \mathrm{MPa}$. Two kinds of specimens are tested, as shown in Figure 1. One is the hourglass specimen, and the other the notch specimen. Before the fatigue test, the surface of the test section is ground and polished to eliminate the machine scratches. The elastic stress concentration factor $K_{t}$ is obtained by the finite element analysis, which is defined as the ratio of the maximum principal stress at the notch root to that of the smallest cross section area in smooth specimen (i.e., nominal stress). The local stress with depth under bending load for both the specimen types is shown in Figure 2. The relative stress gradient $\chi^{\prime}$ at the surface is calculated by $\chi^{\prime}=|\mathrm{d} \sigma(x) / \mathrm{d} x| / \sigma_{\max }[12,17]$, where $\sigma(x)$ denotes the maximum principle stress in depth $x$ from the surface of the notch root or the smallest cross section of the specimen, and $\sigma_{\text {max }}$ denotes the maximum 
principle stress at the surface. The values of $\chi^{\prime}$ at the surface for both the specimen types are calculated from a fourth order polynomial fit of the stress $\sigma(x)$ and the depth $x$ in Figure 2, which are $0.83 \mathrm{~mm}^{-1}$ for the hourglass specimen and $2.01 \mathrm{~mm}^{-1}$ for the notch specimen, respectively.

(a)

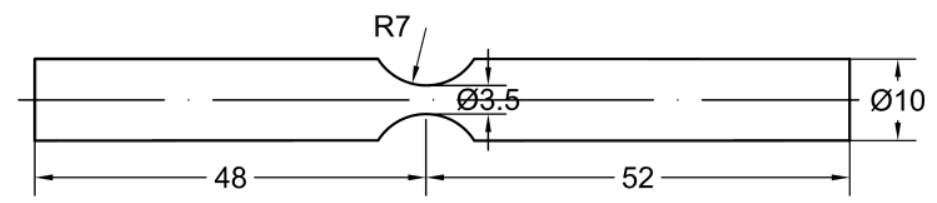

(b)

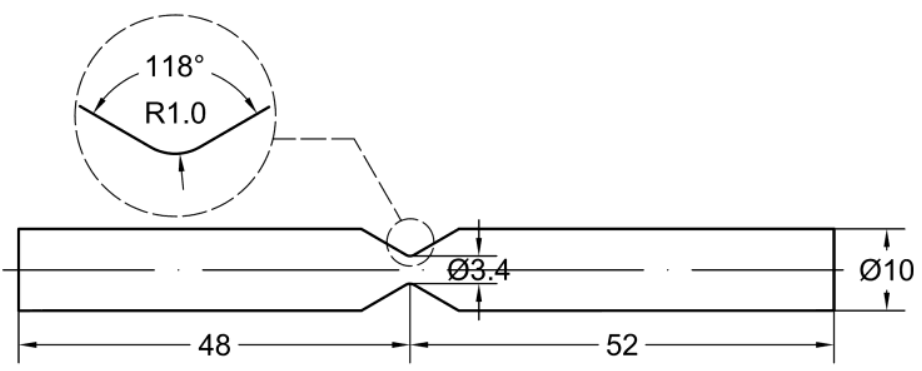

Figure 1. Shape and dimension (in mm) of fatigue specimens. (a) Hourglass specimen with $K_{t}=1.07$; (b) Notch specimen with $K_{t}=1.43$.

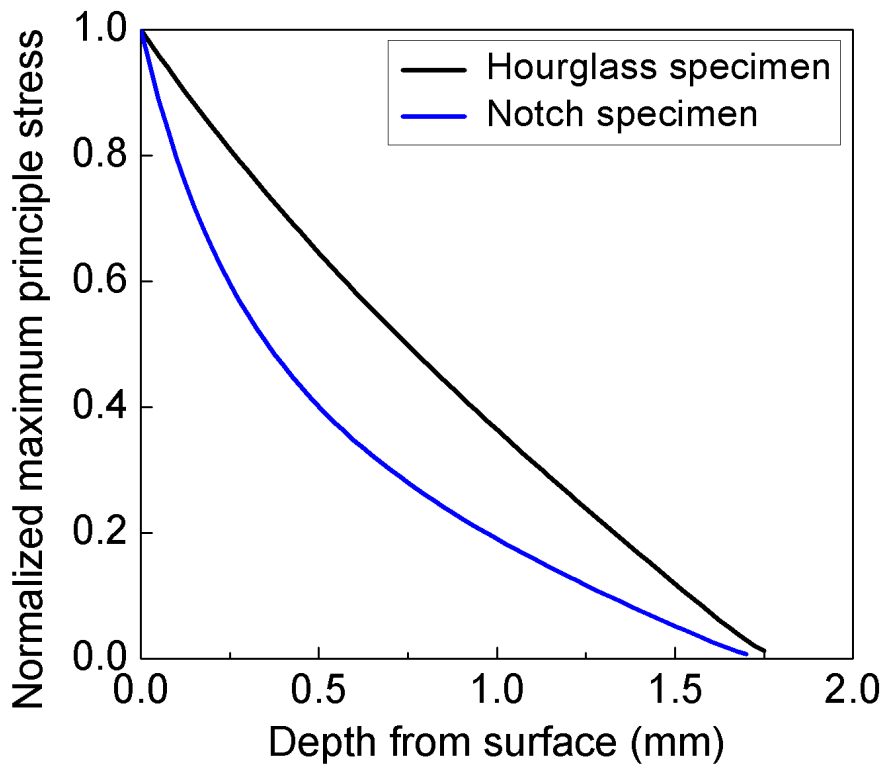

Figure 2. Normalized maximum principle stress with depth from the surface of notch root or the smallest cross section of the specimen.

The fatigue test is conducted on a YRB200 rotating bending machine (Yamamoto Metal Technos Co., LTD., Osaka, Japan) at room temperature. The frequency is $50 \mathrm{~Hz}$ and the stress ratio $R$ is -1 . The fracture surfaces are observed by the JSM-IT300 scanning electron microscope (SEM) (JEOL, Tokyo, Japan).

\section{Experimental Results and Analysis}

The stress-life (S-N) data of the two kinds of specimens are shown in Figure 3. It is seen that the notch has an important influence on the fatigue strength. For the same fatigue life, the notch specimen endures the higher local stress amplitude than that of the hourglass specimen, as shown in Figure $3 \mathrm{~b}$. This might be due to the fact that the control volume (the region subjected to no less than $90 \%$ of the maximum principal stress [17-19] of the specimen) of the notch specimen is relative smaller than that of the hourglass specimen, which reduces the possibility of fatigue failure of the notch specimens. 

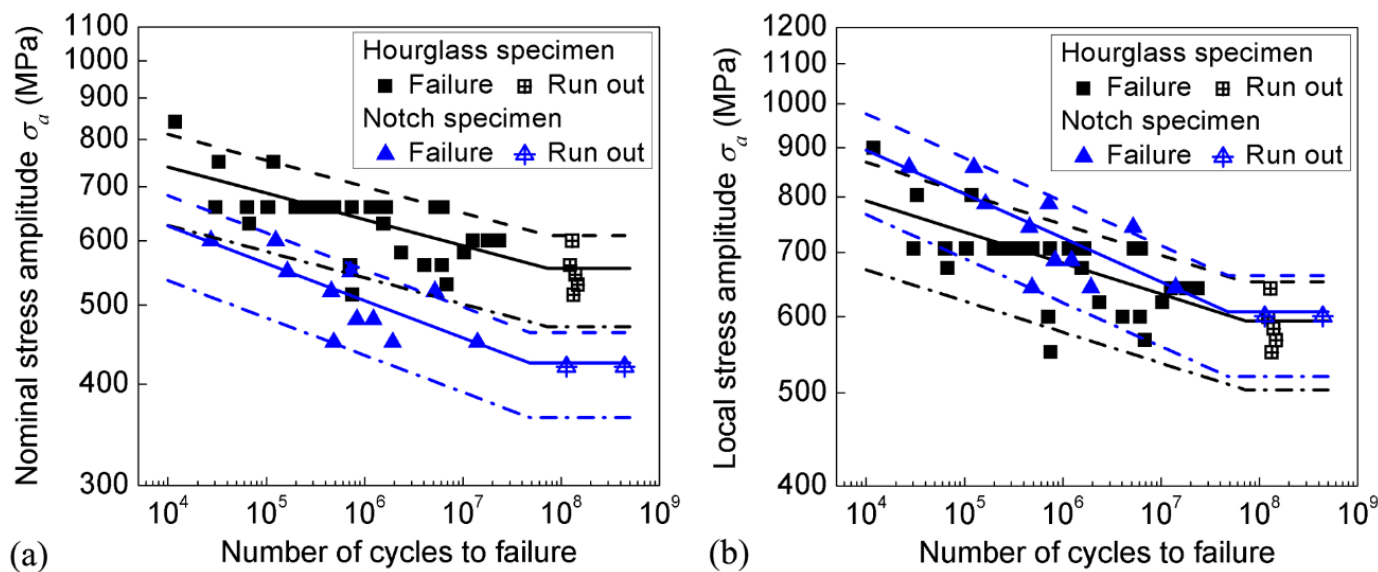

Figure 3. S-N data of hourglass and notch specimens. (a) Nominal stress amplitude versus fatigue life; (b) Local stress amplitude versus fatigue life, in which the solid curve, dashed curve, and the dot and dash curve denote the predicted S-N curves at 50\%, 5\% and 95\% survival probabilities, respectively.

SEM observation indicates that all the hourglass and notch specimens fail from the specimen surface. For both hourglass and notch specimens, single-site crack initiation and multi-site crack initiation are observed at the fracture surface. Figures 4 and 5 show the SEM images of the fracture surface of several hourglass and notch specimens, respectively.
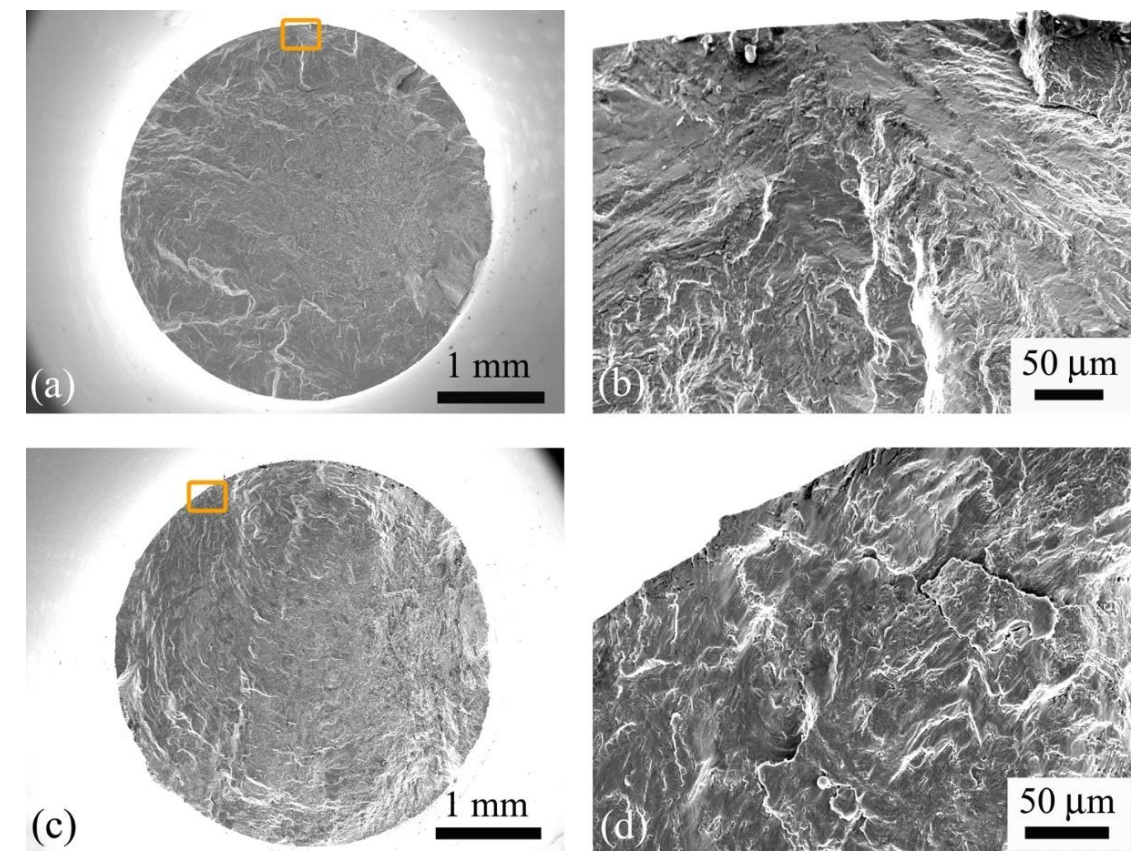

Figure 4. SEM images of fracture surface for hourglass specimens. (a) and (b) Multi-site crack initiation from the specimen surface at nominal stress amplitude $\sigma_{a}=840 \mathrm{MPa}$ and $N_{f}=1.20 \times 10^{4}$; (c) and (d) Single-site crack initiation from the specimen surface at nominal stress amplitude $\sigma_{a}=530 \mathrm{MPa}$ and $N_{f}$ $=6.87 \times 10^{6} ;(\mathbf{b})$ and $(\mathbf{d})$ Magnified view of the rectangular region in (a) and (c), respectively. 

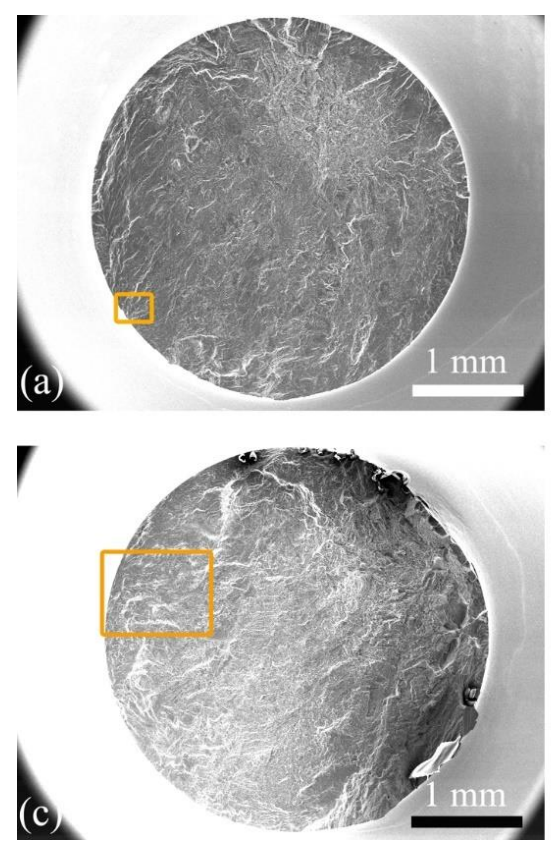
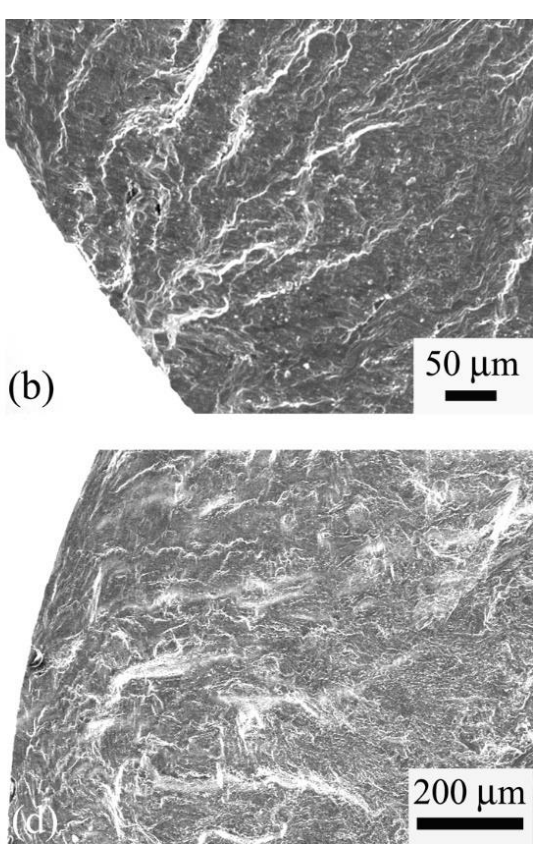

Figure 5. SEM images of fracture surface for notch specimens. (a) and (b) Multi-site crack initiation from the specimen surface at nominal stress amplitude $\sigma_{a}=550 \mathrm{MPa}$ and $N_{f}=1.64 \times 10^{5} ;$ (c) and (d) Single-site crack initiation from the specimen surface at nominal stress amplitude $\sigma_{a}=520 \mathrm{MPa}$ and $N_{f}$ $=5.21 \times 10^{6} ;(\mathbf{b})$ and $(\mathbf{d})$ Magnified view of the rectangular region in (a) and (c), respectively.

\section{A Method for Effects of Specimen Geometry and Loading Condition on Fatigue Strength}

\subsection{Method Construction}

Considering that the fatigue crack generally initiates at the weakest spot in the most highly stressed region (i.e., the control volume) of specimens or components $[17,18]$, it could be assumed that the fatigue strength is dominated by this stress region. So, a normal specimen $\mathrm{A}$ is seen to be composed of a number of reference specimen Cs with very small control volume under the same production procedure through control volume and the fatigue strength of specimen $\mathrm{A}$ at a certain fatigue life is taken as the minimum value of the fatigue strength among $n_{A}$ specimen $C$ under the same fatigue life similar to the Weibull weakest-link method, where $n_{A}$ is an integer part of the ratio of $V_{A} / V_{C}, V_{A}$ and $V_{C}$ are control volumes for specimen $\mathrm{A}$ and specimen $\mathrm{C}$, respectively.

Further, it is assumed that the fatigue strength $\sigma_{C}$ of the referring specimen $C$ under a certain fatigue life follows Weibull distribution, i.e.,

$$
F_{\sigma_{C}}(x)= \begin{cases}1-e^{-\left(\frac{x-\gamma}{\lambda}\right)^{k}} & x \geq 0 \\ 0 & x<0\end{cases}
$$

where $\lambda>0$ is the scale parameter, $k>0$ is the shape parameter and $\gamma \geq 0$ is the location parameter.

Thus, the cumulative distribution function of the fatigue strength $\sigma_{A}$ for specimen A under the same fatigue life satisfies

$$
\begin{aligned}
F_{\sigma_{A}}(x) & =P\left\{\sigma_{A} \leq x\right\} \\
& =P\left\{\min \left\{\sigma_{C, 1}, \sigma_{C, 2,} \cdots, \sigma_{C, n_{A}}\right\} \leq x\right\} \\
& =1-P\left\{\sigma_{C, 1}>x\right\} P\left\{\sigma_{C, 2}>x\right\} \cdots P\left\{\sigma_{C, n_{A}}>x\right\} \\
& =1-\left[1-F_{\sigma_{C}}(x)\right]^{n_{A}} \\
& = \begin{cases}1-e^{-\left(\frac{x-\gamma}{\lambda n_{A}^{-1 / k}}\right)^{k}} & x \geq 0 \\
0 & x<0\end{cases}
\end{aligned}
$$


From Equations (1) and (2), at the same survival probability, we have

$$
1-e^{-\left(\frac{\sigma_{A}-\gamma}{\lambda n_{A}^{-1 / k}}\right)^{k}}=1-e^{-\left(\frac{\sigma_{C}-\gamma}{\lambda}\right)^{k}}
$$

From Equation (3), the fatigue strength of specimen A and that of specimen $\mathrm{C}$ at the same survival probability satisfy

$$
\frac{\sigma_{A}-\gamma}{\sigma_{C}-\gamma}=n_{A}^{-\frac{1}{k}}
$$

Similarly, for the specimen B with control volume $V_{B}$, the fatigue strength $\sigma_{B}$ and that of the referring specimen $C$ at the same survival probability satisfy

$$
\frac{\sigma_{B}-\gamma}{\sigma_{C}-\gamma}=n_{B}^{-\frac{1}{k}}
$$

where $n_{B}$ is an integer part of $V_{B} / V_{C}$ presenting the ratio of the control volume of specimen $\mathrm{B}$ to that of specimen $\mathrm{C}$.

Considering that the control volume of the referring specimen $\mathrm{C}$ is assumed to be very small (e.g., $0.1 \mathrm{~mm}^{3}, 0.01 \mathrm{~mm}^{3}$ ), we have

$$
n_{A}=\frac{V_{A}}{V_{C}} \text { and } n_{B}=\frac{V_{B}}{V_{C}}
$$

From Equations (4)-(6), we have the relation for the fatigue strength of specimens with different control volumes at the same survival probability, i.e.,

$$
\frac{\sigma_{A}-\gamma}{\sigma_{B}-\gamma}=\left(\frac{V_{A}}{V_{B}}\right)^{-\frac{1}{k}}
$$

For the surface induced fatigue failure, it might be more appropriate to take the critical part of the specimen surface (i.e., control surface) with a certain thickness $h$ (e.g., the magnitude of several grains) [19]. In this case, Equation (7) becomes

$$
\frac{\sigma_{A}-\gamma}{\sigma_{B}-\gamma}=\left(\frac{S_{A}}{S_{B}}\right)^{-\frac{1}{k}}
$$

where $S_{A}$ and $S_{B}$ denote the control surface of specimen A and specimen B, respectively.

As a special case, for the two-parameter Weibull distribution, i.e., the location parameter $\gamma=0$, Equations (7) and (8) change to

$$
\begin{aligned}
& \frac{\sigma_{A}}{\sigma_{B}}=\left(\frac{V_{A}}{V_{B}}\right)^{-\frac{1}{k}} \\
& \frac{\sigma_{A}}{\sigma_{B}}=\left(\frac{S_{A}}{S_{B}}\right)^{-\frac{1}{k}}
\end{aligned}
$$

\subsection{Analysis and Discussion}

From Equation (1), the scatter of fatigue strength decreases with decreasing the scale parameter $\lambda$ for the same shape parameter $k$. To predict the fatigue strength of the large specimen through that of the small specimen, we have $n_{A}>1$, i.e., $\lambda n_{A}{ }^{-1 / k}<\lambda$ in Equation (2). This indicates that the scatter of the fatigue strength for the large specimen is smaller than that for the small specimen.

Further, Equations (7)-(10) indicate that the effects of specimen geometry and loading condition on the fatigue strength depend not only the control volume ratio, but also the shape parameter $k$ of Weibull distribution for the fatigue strength. Figure 6 shows the relation between the value of $\left(\sigma_{A}-\gamma\right) /\left(\sigma_{B}-\gamma\right)$ and the ratio of control volume $V_{A} / V_{B}$ described in Equation (7) for different shape 
parameter $k$. It is seen that the value of $\left(\sigma_{A}-\gamma\right) /\left(\sigma_{B}-\gamma\right)$ decreases with increasing the ratio of control volume, i.e., the fatigue strength decreases with the increase of control volume. For the same $V_{A} / V_{B}$, the value of $\left(\sigma_{A}-\gamma\right) /\left(\sigma_{B}-\gamma\right)$ increases with increasing the shape parameter $k$, i.e., the decrease of the fatigue strength is reduced with the increase of the shape parameter $k$. This suggests that the shape parameter $k$ of Weibull distribution of the fatigue strength reflects the degree of influence of specimen geometry and loading condition on the fatigue strength. Figure 6 also indicates that the value of $\left(\sigma_{A}-\gamma\right) /\left(\sigma_{B}-\gamma\right)$ tends to zero when the control volume tends to infinity, i.e., the fatigue strength tends to the minimum value $\gamma$ in Equation (7). This is in agreement with the fact that fatigue strength cannot decrease infinitely with the increase of the control volume (specimen size).

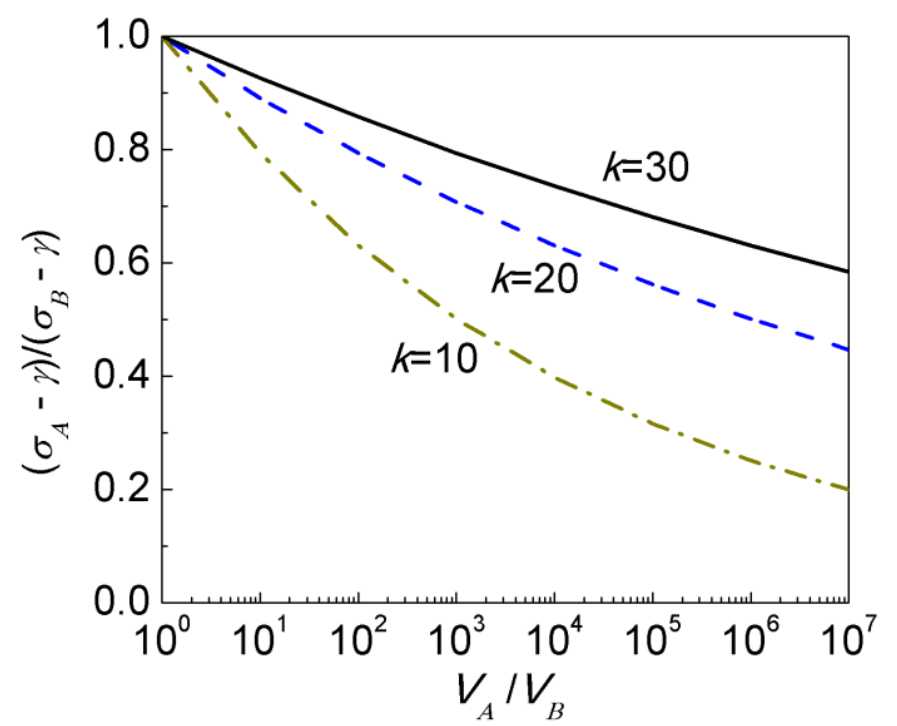

Figure 6. Value of $\left(\sigma_{A}-\gamma\right) /\left(\sigma_{B}-\gamma\right)$ versus $V_{A} / V_{B}$ in Equation (7) at different shape parameter $k$.

It is noted that the present formula Equation (9) is of the same form as the highly stressed volume method derived from the empirical equation $[10,11,17]$. The difference is that the present formula is derived based on the statistical theory, and the parameter reflecting the effects of specimen geometry and loading condition could be obtained as the shape parameter of Weibull distribution of the fatigue strength of specimens, while for the existing highly stressed volume method, the parameter needs to be determined by fitting the highly stressed volume and the fatigue strength. The present method is also different from the Weibull weakest-link method. For the Weibull weakest-link method $[4,17,20]$, the effective stress amplitude is related to the volume $V$ of a component and the stress distribution in volume $V$, which needs to make an integral of the stress in volume $V$, while for the present method based on the control volume concept, the effective stress amplitude is related to the value of the highly stressed volume and the maximum stress [17].

\section{Comparison with Experimental Results}

\subsection{Probabilistic Stress-Life (P-S-N) Curve Prediction}

For the application of the proposed method (probabilistic control volume method), we need to determine the control volume and the shape parameter of Weibull distribution for the fatigue strength at first. Usually, the fatigue tests are performed for the specimens at different stress levels, and there are not enough fatigue strength data at the same fatigue life for statistical analysis. In this case, the bilinear model for the S-N curve is considered [21,22], i.e.,

$$
\log _{10} \sigma= \begin{cases}a \log _{10} N+A, & N<N_{0} \\ B, & N \geq N_{0}\end{cases}
$$


where $a, A$ and $B$ are constants, $N_{0}$ is the number of cycles at the knee point of the curve.

Equation (11) could be written as

$$
\log _{10} \sigma= \begin{cases}a\left(\log _{10} N-\log _{10} N_{0}\right)+B, & N<N_{0} \\ B, & N \geq N_{0}\end{cases}
$$

where the values of $a, B$ and $N_{0}$ could be obtained by iterative calculation to minimize the value of the following equation

$$
\sum_{N_{k}<N_{0}}\left[\log _{10} \sigma_{k}-a \log _{10}\left(N_{k} / N_{0}\right)-B\right]^{2}+\sum_{N_{k} \geq N_{0}}\left(\log _{10} \sigma_{k}-B\right)^{2}
$$

where $\sigma_{k}$ is the fatigue strength, $N_{k}$ is the associated fatigue life, $k=1,2, \ldots, n$, and $n$ is the number of specimens used for analysis.

By using Equation (12), the fatigue strength $\sigma_{k}$ at an arbitrary fatigue life $N_{k}$ could be transformed to the fatigue strength $\sigma_{k}^{\prime}$ at a given fatigue life $N_{k}^{\prime}$, i.e.,

$$
\log _{10} \sigma_{k}^{\prime}=\left\{\begin{array}{l}
a \log _{10} \frac{N_{k}^{\prime}}{N_{k}}+\log _{10} \sigma_{k}, N_{k}<N_{0} \\
a \log _{10} \frac{N_{k}^{\prime}}{N_{0}}+\log _{10} \sigma_{k}, N_{k} \geq N_{0}
\end{array} \quad \text { for } N_{k}^{\prime}<N_{0}\right.
$$

or

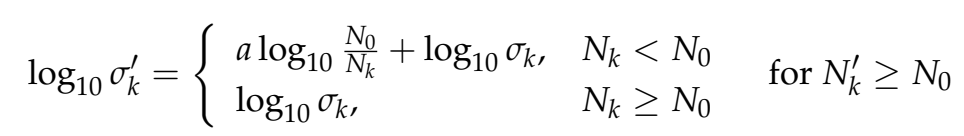

Then, the distribution form of the fatigue strength at different fatigue lifetimes could be analyzed and the P-S-N curve is determined.

\subsection{Comparison with Present Experimental Data}

A comparison of the predicted P-S-N curves with the present experimental data for the hourglass specimen and the notch specimen is shown in Figure 3, in which $a=-0.0323, B=2.740$ and $N_{0}=$ $7.24 \times 10^{7}$ for the hourglass specimen and $a=-0.0458, B=2.623$ and $N_{0}=4.79 \times 10^{7}$ for the notch specimen in Figure $3 \mathrm{a}, a=-0.0323, B=2.769$ and $N_{0}=7.24 \times 10^{7}$ for the hourglass specimen and $a=$ $-0.0458, B=2.779$ and $N_{0}=4.79 \times 10^{7}$ for the notch specimen in Figure 3b. Here, the two-parameter Weibull distribution is assumed for the fatigue strength. The scale parameter and the shape parameter are obtained via Matlab software version 7.8.0 (MathWorks, Inc., Novi, Michigan, MI, USA). It is seen that the predicted $50 \%$ survival probability curve is, in general, in the middle of the scattered experimental data, and almost all the experimental data are within the predicted $95 \%$ and $5 \%$ survival probability curves, indicating that the predicted P-S-N curves accord with the experimental data.

Considering that all the specimens fail from the surface for the present titanium alloy, the present method with control surface (i.e., Equation (10)) is used for the effect of notch on the fatigue strength. The control surface is taken as the region subjected to no less than $90 \%$ of the maximum principal stress [17-19] and calculated by finite element analysis, which is $18.78 \mathrm{~mm}^{2}$ for the hourglass specimen and $4.49 \mathrm{~mm}^{2}$ for the notch specimen.

Figure 7 shows a comparison of the predicted P-S-N curves with the present experimental data for the notch specimen by using the fatigue strength data of the hourglass specimen. It is seen that the predicted P-S-N curves accord with the experimental data. 


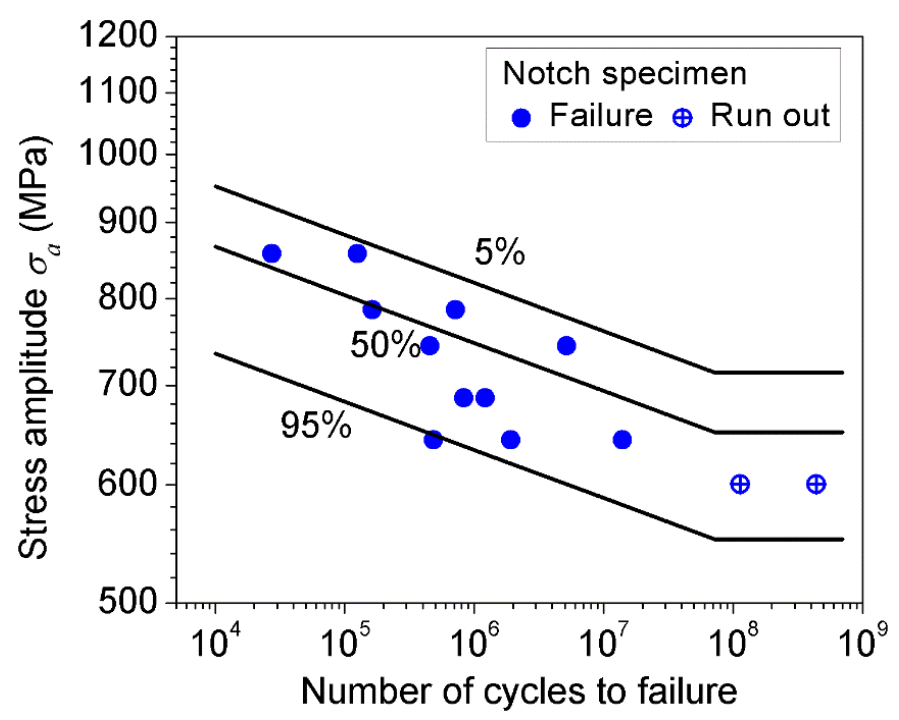

Figure 7. Comparison of predicted P-S-N curves with present experimental data for the notch specimen by using the fatigue strength data of the hourglass specimen.

\subsection{Comparison with Experimental Data of a High Strength Steel}

Figure 8 shows the comparison of the predicted P-S-N curves with the experimental data of the hourglass specimen with $\phi 3 \mathrm{~mm}$ in the minimum gauge section for a high strength steel JIS-SCM440 under ultrasonic fatigue test in literature [23], in which $a=-0.0483, B=2.895$ and $N_{0}=8.71 \times 10^{7}$. Figure 8 shows a good agreement for the predicted P-S-N curves with the experimental data.

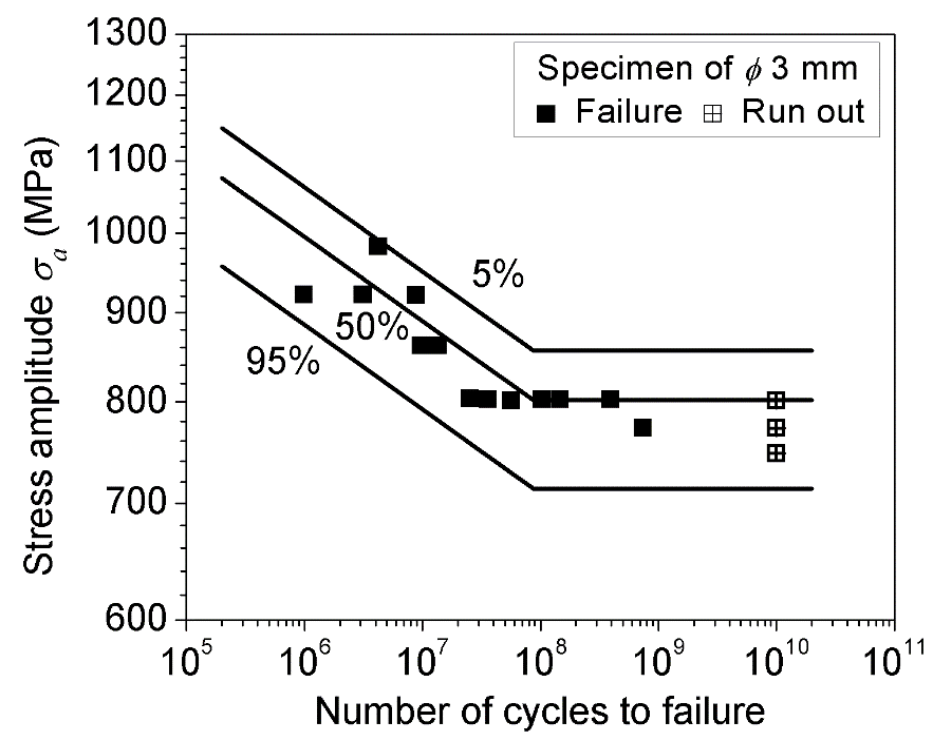

Figure 8. Comparison of predicted P-S-N curves with experimental data for a high strength steel JIS-SCM440 in literature [23].

The comparison of the predicted P-S-N curves with experimental data for the effect of specimen size on the fatigue strength is shown in Figure 9, in which the experimental data of the hourglass specimen with $\phi 3 \mathrm{~mm}$ in the minimum gauge section is used to predict the fatigue strength of the hourglass specimen with $\phi 7 \mathrm{~mm}$ in the minimum gauge section and the dogbone specimen with $\phi 8 \times 10 \mathrm{~mm}$ in straight section. The control volume (the region no less than $90 \%$ of the maximum stress) is used on account of the fact that all the specimens fail from the interior [23], which is $33 \mathrm{~mm}^{3}$ for the hourglass specimen with $\phi 3 \mathrm{~mm}$ in the minimum gauge section, $254 \mathrm{~mm}^{3}$ for the hourglass specimen with $\phi 7 \mathrm{~mm}$ in the minimum gauge section, and $781 \mathrm{~mm}^{3}$ for the dogbone specimen with 
$\phi 8 \times 10 \mathrm{~mm}$ in straight section as given in literature [23]. It is seen in Figure 9 that the predicted P-S-N curves for the effect of specimen size on the fatigue strength are in good agreement with the experimental data.
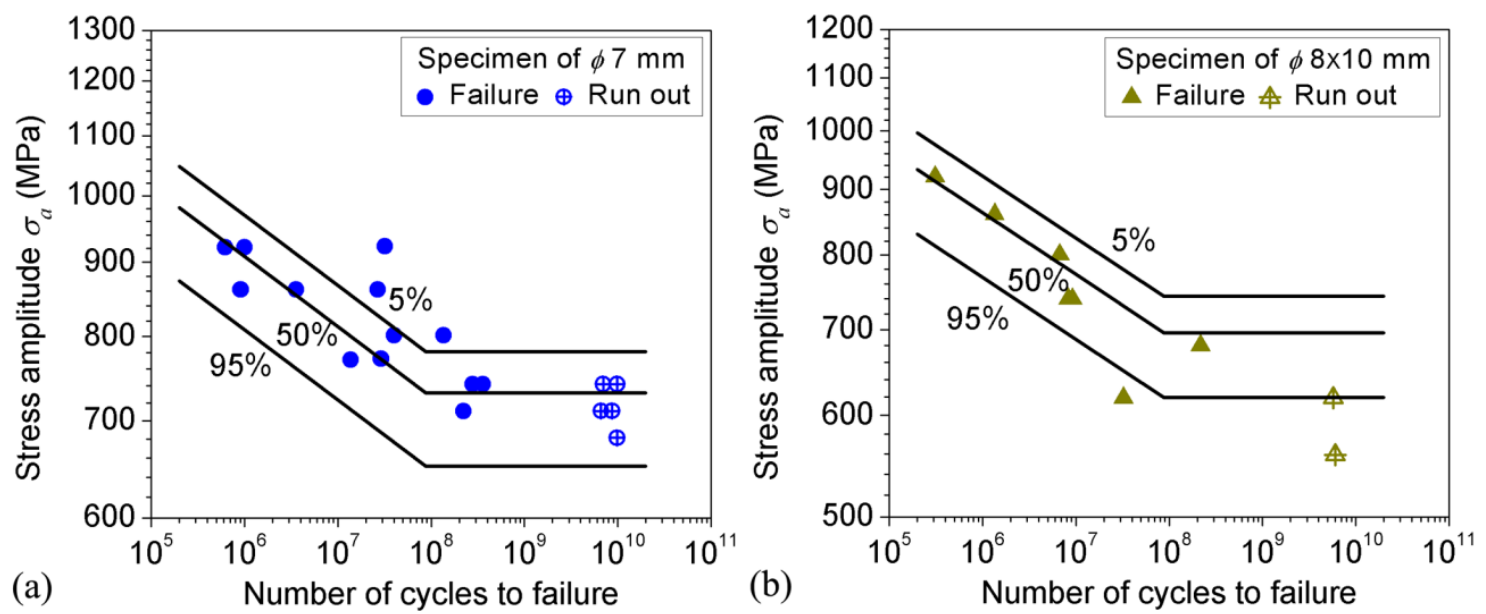

Figure 9. Comparison of predicted P-S-N curves with experimental data in literature [23] by using the fatigue strength data from the hourglass specimen with $\phi 3 \mathrm{~mm}$ in the minimum gauge section. (a) Comparison for the hourglass specimen with $\phi 7 \mathrm{~mm}$ in the minimum gauge section; (b) Comparison for the dogbone specimen with $\phi 8 \times 10 \mathrm{~mm}$ in straight section.

\subsection{Comparison with Experimental Data of Full Scale Axles}

For a further validation of the proposed probabilistic control volume method, it is used to predict the fatigue strength of the full scale EA4T axles by using the fatigue strength data tested for small specimens in literature.

Figure 10 shows a comparison of the predicted P-S-N curves with the experimental data for the small specimen in literature [24], in which $a=-0.0487, B=2.572$ and $N_{0}=1.66 \times 10^{6}$. It is seen that, the predicted $50 \%$ survival probability curve is generally in the middle of the scattered experimental data, and most of the experimental data are within the predicted $95 \%$ and $5 \%$ survival probability curves, indicating that the predicted P-S-N curves accord well with the experimental data.

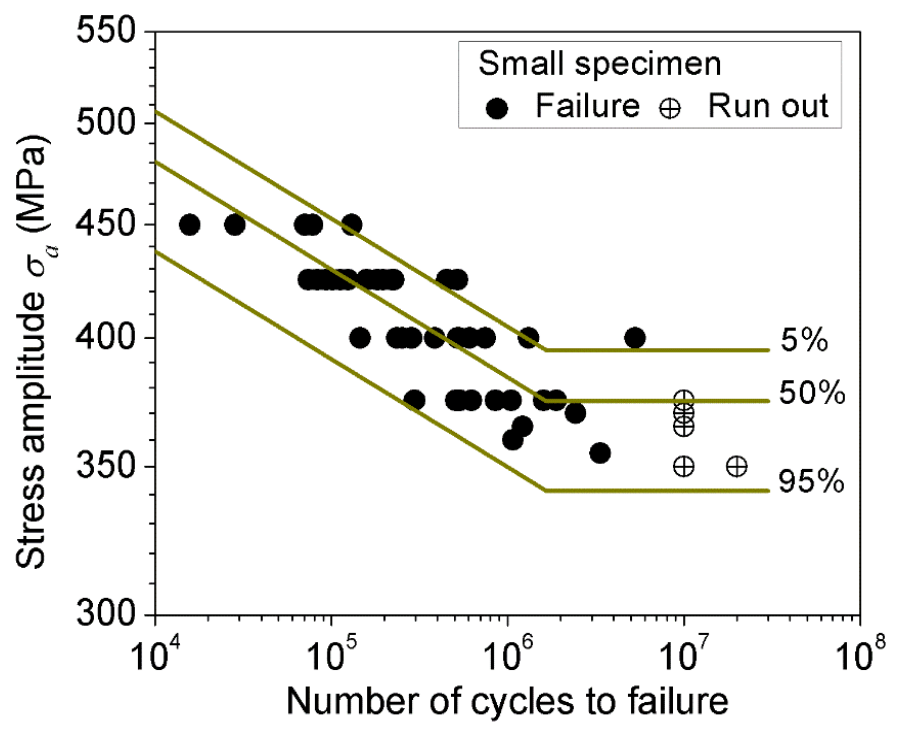

Figure 10. Comparison of predicted P-S-N curves with experimental data for the small specimen in literature [24]. 
Figure 11 shows the comparison of the predicted P-S-N curves with the experimental data of the full scale EA4T axles [24] by using the fatigue strength data of the small specimen [24]. Here, the control surface is considered, which is $9656.84 \mathrm{~mm}^{2}$ for the full scale axle and $227.85 \mathrm{~mm}^{2}$ for the small specimen. The shape and dimension of the full-scale axle is according to work by Cervello [25], which has the same transition geometry as drawing A1 and subjects to rotating bending loading type. The small specimen is according to work by Filippini et al. [26], which has the same test section and subjects to axial loading. The Young's modulus is $206 \mathrm{GPa}$ and Poisson's ratio is 0.29 in the calculation. It is seen from Figure 11 that the predicted P-S-N curves for the effects of specimen geometry and loading condition on the fatigue strength accord with the experimental data. In particular, the predicted fatigue strength at $50 \%$ survival probability is $328 \mathrm{MPa}$, which is in good agreement with the average free body fatigue strength (limit) $307 \mathrm{MPa}$ of the full scale axle with standard surface finishing by the stair-case method [25], the relative error of the former to the latter is $6.8 \%$.

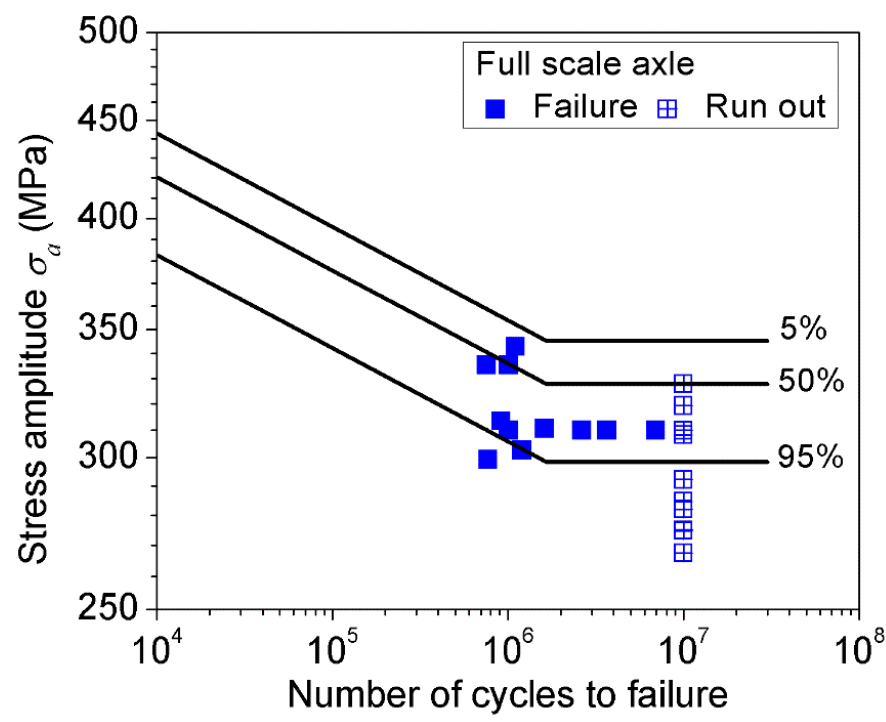

Figure 11. Comparison of predicted P-S-N curves with experimental data of full scale EA4T axles [24] by using the fatigue strength data from the small specimen [24].

It is noted that for the fatigue failure of materials dominated by the multiple crack propagation with mutual interactions and coalescences, the large specimen might endure longer crack propagation life than that of the small specimen [6]. In this case, the present method is invalid for the effects of specimen geometry and loading condition on the fatigue strength.

\section{Conclusions}

In this paper, the effect of notch on the fatigue behavior of a high strength titanium alloy Ti-6Al-2Sn-2Zr-3Mo- $X$ is studied at first by rotating bending fatigue test. It indicates that the notch has important influence on the fatigue strength but no influence on the crack initiation mechanism. Compared with the hourglass specimen, the notch specimen shows the higher local fatigue strength at the same fatigue life.

Then, a probabilistic control volume method is developed for the effects of specimen geometry and loading condition on the fatigue strength based on the statistical theory and the concept of control volume. By assuming that a normal specimen is seen composed of a number of referring specimens through control volume and that the fatigue strength of the referring specimen follows Weibull distribution, a simple formula is obtained for correlating the fatigue strength of specimens with different control volumes, i.e., $\left(\sigma_{A}-\gamma\right) /\left(\sigma_{B}-\gamma\right)=\left(V_{A} / V_{B}\right)^{-1 / k}$, where $\sigma$ denotes the fatigue strength, $V$ denotes the control volume (e.g., the region no less than $90 \%$ of the maximum principal stress), $\gamma$ and 
$k$ denote the location parameter and shape parameter of Weibull distribution of the fatigue strength, respectively, and subscripts A and B denote the quantities for specimens A and B, respectively.

The predicted results for the effect of specimen geometry on the fatigue strength accord with the present experimental data for a titanium alloy Ti-6Al-2Sn-2Zr-3Mo-X and the data for a high strength steel JIS-SCM440 in literature. The method is further used to predict the fatigue strength of full scale EA4T axles by using the fatigue strength data tested for small specimens in literature. The predicted fatigue strength at $50 \%$ survival probability is in good agreement with the average fatigue strength of the full scale axle by the stair-case method, the relative error of which is $6.8 \%$.

The paper also indicates that for the surface induced fatigue failure, it might be appropriate to use the control surface with a certain thickness in the control volume method, while for the interior induced fatigue failure, the control volume might be more applicable.

Author Contributions: Conceptualization, C.S.; methodology, C.S.; investigation, C.S.; formal analysis, C.S. and Q.S.; writing - original draft preparation, C.S. and Q.S.; writing-review and editing, C.S. and Q.S.; supervision, C.S.; funding acquisition, C.S.

Funding: This research was funded by the National Key Research and Development Program of China "Genera Design, Construction and Sea Trial of Full Ocean Deep Manned Submersible", grant number 2016YFC0300600 and the Strategic Priority Research Program of the Chinese Academy of Sciences, grant numbers XDB22040503, XDB22020201, XDB22020200.

Conflicts of Interest: The authors declare no conflict of interest.

\section{References}

1. Beretta, S.; Ghidini, A.; Lombardo, F. Fracture mechanics and scale effects in the fatigue of railway axles. Eng. Fract. Mech. 2005, 72, 195-208. [CrossRef]

2. Nakajima, M.; Tokaji, K.; Itoga, H.; Shimizu, T. Effect of loading condition on very high cycle fatigue behavior in a high strength steel. Int. J. Fatigue 2010, 32, 475-480. [CrossRef]

3. Akiniwa, Y.; Miyamoto, N.; Tsuru, H.; Tanaka, K. Notch effect on fatigue strength reduction of bearing steel in the very high cycle regime. Int. J. Fatigue 2006, 28, 1555-1565. [CrossRef]

4. Wormsen, A.; Sjödin, B.; Härkegård, G.; Fjeldstad, A. Non-local stress approach for fatigue assessment based on weakest-link theory and statistics of extremes. Fatigue Fract. Eng. Mater. Struct. 2007, 30, 1214-1227. [CrossRef]

5. Findley, W.N. Research note: an explanation of size effect in fatigue of metals. J. Mech. Eng. Sci. 1972, 14, 424-425. [CrossRef]

6. Zhu, S.P.; Foletti, S.; Beretta, S. Evaluation of size effect on strain-controlled fatigue behavior of a quench and tempered rotor steel: Experimental and numerical study. Mater. Sci. Eng. A 2018, 735, 423-435. [CrossRef]

7. Diemar, A.; Thumser, R.; Bergmann, J.W. Determination of local characteristics for the application of the Weakest-Link Model. Materialwiss. Werkstofftech. 2005, 36, 204-210. [CrossRef]

8. Leitner, M.; Garb, C.; Remes, H.; Stoschka, M. Microporosity and statistical size effect on the fatigue strength of cast aluminium alloys EN AC-45500 and 46200. Mater. Sci. Eng. A 2017, 707, 567-575. [CrossRef]

9. Furuya, Y. Specimen size effects on gigacycle fatigue properties of high-strength steel under ultrasonic fatigue testing. Scr. Mater. 2008, 58, 1014-1017. [CrossRef]

10. Kuguel, R.A. A relation between theoretical stress concentration factor and fatigue notch factor deduced from the concept of highly stressed volume. ASTM Proc. 1961, 61, 732-748.

11. Lin, C.K.; Lee, W.J. Effects of highly stressed volume on fatigue strength of austempered ductile irons. Int. J. Fatigue 1998, 20, 301-307. [CrossRef]

12. Leitner, M.; Vormwald, M.; Remes, H. Statistical size effect on multiaxial fatigue strength of notched steel components. Int. J. Fatigue 2017, 104, 322-333. [CrossRef]

13. Lanning, D.B.; Nicholas, T.; Palazotto, A. HCF notch predictions based on weakest-link failure models. Int. J. Fatigue 2003, 25, 835-841. [CrossRef]

14. Bažant, Z.P.; Novák, D. Probabilistic nonlocal theory for quasibrittle fracture initiation and size effect. I: theory. J. Eng. Mech. 2000, 126, 166-174. [CrossRef]

15. Makkonen, M. Statistical size effect in the fatigue limit of steel. Int. J. Fatigue 2001, 23, 395-402. [CrossRef] 
16. Susmel, L.; Taylor, D. A novel formulation of the theory of critical distances to estimate lifetime of notched components in the medium-cycle fatigue regime. Fatigue Fract. Eng. Mater. Struct. 2007, 30, 567-581. [CrossRef]

17. Härkegård, G.; Halleraker, G. Assessment of methods for prediction of notch and size effects at the fatigue limit based on test data by Böhm and Magin. Int. J. Fatigue 2010, 32, 1701-1709. [CrossRef]

18. Murakami, Y. Metal Fatigue: Effects of Small Defects and Nonmetallic Inclusions; Elsevier Science Ltd.: Oxford, UK, 2002; pp. 333-336.

19. Sun, C.; Zhang, X.; Liu, X.; Hong, Y. Effects of specimen size on fatigue life of metallic materials in high-cycle and very-high-cycle fatigue regimes. Fatigue Fract. Eng. Mater. Struct. 2016, 39, 770-779. [CrossRef]

20. Hertel, O.; Vormwald, M. Statistical and geometrical size effects in notched members based on weakest-link and short-crack modelling. Eng. Fract. Mech. 2012, 95, 72-83. [CrossRef]

21. Hanaki, S.; Yamashita, M.; Uchida, H.; Zako, M. On stochastic evaluation of S-N data based on fatigue strength distribution. Int. J. Fatigue 2010, 32, 605-609. [CrossRef]

22. Pollak, R.D.; Palazotto, A.N. A comparison of maximum likelihood models for fatigue strength characterization in materials exhibiting a fatigue limit. Probabilist. Eng. Mech. 2009, 24, 236-241. [CrossRef]

23. Furuya, Y. Size effects in gigacycle fatigue of high strength steel under ultrasonic fatigue testing. Procedia Eng. 2010, 2, 485-490. [CrossRef]

24. Beretta, S.; Regazzi, D. Probabilistic fatigue assessment for railway axles and derivation of a simple format for damage calculations. Int. J. Fatigue 2016, 86, 13-23. [CrossRef]

25. Cervello, S. Fatigue properties of railway axles: New results of full-scale specimens from Euraxles project. Int. J. Fatigue 2016, 86, 2-12. [CrossRef]

26. Filippini, M.; Luke, M.; Varfolomeev, I.; Regazzi, D.; Beretta, S. Fatigue strength assessment of railway axles considering small-scale tests and damage calculations. Procedia Struct. Integrity 2017, 4, 11-18. [CrossRef]

(C) 2018 by the authors. Licensee MDPI, Basel, Switzerland. This article is an open access article distributed under the terms and conditions of the Creative Commons Attribution (CC BY) license (http:/ / creativecommons.org/licenses/by/4.0/). 